\title{
A MODEL SIMULATION OF 20 YEARS OF NORTHERN HEMISPHERE SEA-ICE FLUCTUATIONS
}

\author{
by \\ John E. Walsh, \\ (Department of Atmospheric Sciences, University of Illinois, Urbana, Illinois 61801, U.S.A.) \\ William D. Hibler III \\ (U.S. Army Cold Regions Research and Engineering Laboratory, 72 Lyme Road, Hanover, \\ New Hampshire 03755, U.S.A.) \\ and Becky Ross \\ (Department of Atmospheric Sciences, University of Illinois, Urbana, Illinois 61801, U.S.A.)
}

\section{ABSTRACT}

A dynamic-thermodynamic sea-ice model (Hibler 1979) is used to simulate northern hemisphere sea ice for a 20 -year period, 1961 to 1980 . The model is driven by daily atmospheric grids of sea-level pressure (geostrophic wind) and by temperatures derived from the Russian surface temperature data set. Among the modifications to earlier formulations are the inclusion of snow cover and a multilevel ice-thickness distribution in the thermodynamic computations.

The time series of the simulated anomalies show relatively large amounts of ice during the early 1960 s and middle 1970s, and relatively small amounts during the late 1960 s and early 1970s. The fluctuations of ice mass, both in the entire domain and in individual regions, are more persistent than are the fluctuations of ice-covered area. The ice dynamics

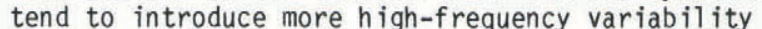
into the regional (and total) amounts of ice mass. The simulated annual ice export from the Arctic Bas in into the East Greenland Sea varies interannually by factors of 3 to 4 .

\section{INTRODUCTION}

Studies of Arctic sea-ice variability on the interannual and decadal scales have heretofore been based almost exclusively on statistical or empirical analyses of observational data (e.g. Sanderson 1975, Kelly 1978, Rogers 1978, Walsh and Johnson 1979, Lemke and others 1980 , Smirnov 1980). The statistical analyses are severely constrained by the observational data, which are 1 imited to approximately 15 years of satellite-derived hemispheric coverage or to longer periods of irregular coverage for portions of the Arctic periphery. Moreover, the observational data are 1 imited almost exclusively to areal ice extent. The data therefore do not permit analyses of cl imatically relevant variables such as ice thickness, horizontal heat and mass transports, and vertical heat fluxes.

Numerical modeling provides an alternative approach to the large-scale variability of sea ice. When driven by time-dependent fields of atmospheric data, dynamic-thermodynamic sea-ice models provide fields of ice concentration, thickness and velocity which permit the construction of mass budgets for various high-latitude regions. Relatively few model studies have addressed sea-ice fluctuations over time periods longer than several weeks. Monthly climatological temperature and pressure fields were used in a series of equilibrium simulations by Parkinson and Washington (1979) and Parkinson and Kellogg (1979). In the latter study, the sensitivity of the ice to a large-scale warming was examined by imposing spatially and temporally invariant increases of surface air temperature. A $5 \mathrm{~K}$ warming of this $k$ ind resulted in a complete disappearance of the Arctic ice during summer. Manabe and Stouffer (1980) performed a series of multiyear simulations with a coupled ice-ocean-atmosphere model. Sea ice was represented as a motionless slab without leads in this experiment designed to address the sensitivity to a $\mathrm{CO}_{2}$-induced warming. While the $\mathrm{CO}_{2}$ sensitivity was indeed partially attributable to seaice effects, it should be noted that the control experiment (present $\mathrm{CO}_{2}$ ) produced a winter ice cover that is approximately twice as extensive as observed in the Arctic but only half as extensive as observed in the Antarctic (Manabe and Stouffer 1980: fig.11). In another coupled model simulation, Washington and others (1980) employed a simpl if ied thermodynamic model in which ice growth and decay were determined from precipitation and/or flux imbalances. Sea-ice dynamics were not included. The discrepancies between the simulated and observed ice coverage included an excess of simulated ice in the North Atlantic during the non-summer months. In the central Arctic, the simulated ice thickness $(\sim 1.5 \mathrm{~m})$ was considerably smaller than the values of 3 to $4 \mathrm{~m}$ deduced from submarine data (LeSchack and others 1971).

Hibler $(1979,1980)$ used observed forcing data from a single year to drive a dynamic-thermodynamic model in a series of periodic equilibrium simulations for the Arctic Basin. The same model was used by Hibler and Walsh (1982) in simulations of northernhemisphere sea-ice fluctuations during the period 1973-75. The latter simulations yielded a seasonal cycle with excessive amounts of ice in the North Atlantic during winter and with somewhat excessive 
amounts of open water in the central Arctic during summer. Despite these seasonal biases, the simulated and observed interannual fluctuations were similar in magnitude and positively correlated. Considerable interannual variability was apparent in the three-year simulation. While these simulations established the feasibility of using a dynamicthermodynamic sea-ice model for studying sea-ice fluctuations, the conclusions were subject to uncertainties concerning $(i)$ the representativeness of the three-year sample of fluctuations, and ( $i i)$ the impact of the model "spin-up" on the threeyear results. The present work extends these earlier simulations to the decadal scale (20 years) and incorporates several changes in the model thermodynamics (section 2). The objective of the work is an analys is of large-scale multiyear sea icefluctuations in the context of the mass budgets of various sectors of the high-latitude ocean. As noted earlier, such an analys is must rely heavily on modelgenerated fields of ice thickness, compactness and velocity.

\section{MODEL SUMMARY}

The essential features of the model are (a) a momentum balance based on geostrophically-derived air and water stresses, Coriol is force, ocean tilt, internal ice stress and inertial terms, (b) an ice rheology based on a viscous-plastic constitutive law and an ice-strength parameter $p^{*},(c)$ an icethickness distribution characterized by the compactness $A$ and the mean ice thickness $h$ averaged over an entire grid cell, (d) a thermodynamic code in which vertical growth rates are estimated from heat-budget computations at the top and bottom surfaces of the ice and from the heat stored in a motionless oceanic boundary layer. Details of the model formulation are given by $\mathrm{Hibler}(1979,1980)$. Except for the modif $i-$ cations described below, the present simulations were based on the same version of the model and spatial grid used by $\mathrm{H}$ ibler and Walsh (1982).

2(a). Model doma in

The domain used by Hibler and Walsh (1982) has been expanded by $\sim 600 \mathrm{~km}$ to include a larger portion of the Pacific sub-Arctic. The simulations are now performed on a $38 \times 31$ grid with a resolution of $222 \mathrm{~km}$ (Fig.1). While the use of a relatively coarse horizontal resolution is dictated by the availability of computer resources, simulations driven by periodic forcing on a $125 \mathrm{~km}$ grid covering the Arctic Basin (Hibler 1979) produced results which were quite compatible with those obtained for the same region in the present work.

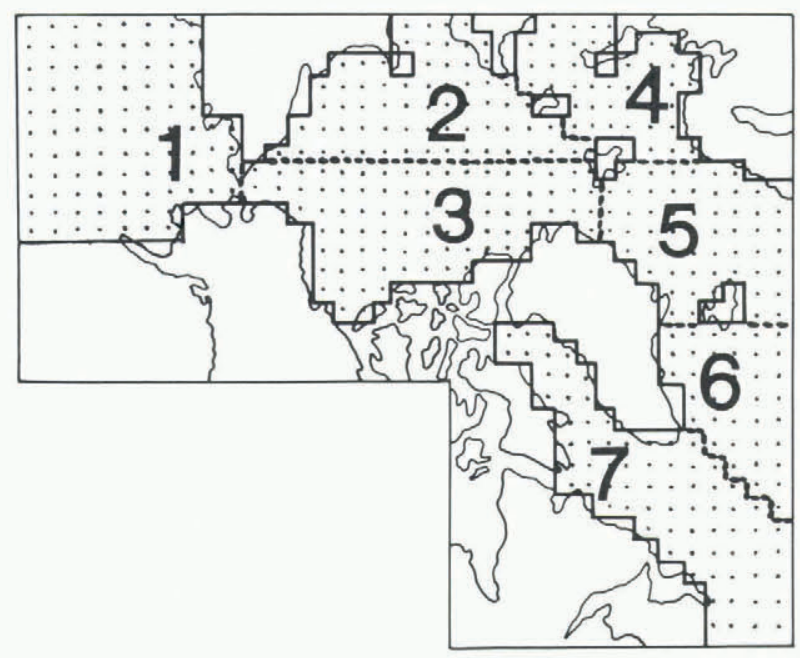

Fig.1. The model grid and numbered regions.

\section{2(b). Explicit treatment of snow cover}

In the previous simulations snow cover was parameterized only through the surface albedo, which was assigned a value corresponding to ice or snow when the air temperature was above or below freezing, respectively. Snow is now accumulated during the non-summer months according to the prescribed accumulation rates of Parkinson and Washington (1979). The thermal conductivity of the snow/ice layer is represented by a single value corresponding to a weighted sum of the conductivities of snow and ice; the weighting factors are the snow- and ice-fractions of the total thickness. When the air temperature is above freezing, the snow must melt completely before the ice thickness is reduced by surface melt. The prescribed surface albedos of snow and ice are 0.80 and 0.65 , respectively. 2 (c). Multilevel thermodynamic computations

Thermodynamic computations were previously performed for two levels: open water $(h=0)$ and an effective thickness $h_{\text {eff }}$, representing the mean thickness of ice in the ice-covered portion of the grid cell. In order to incorporate the strong thickness-dependence of ice-growth rates (e.g. Maykut 1982), heff is replaced by a seven-level distribution of thicknesses equally spaced between 0 and $2 \mathrm{~h}$ eff. While a more realistic thickness distribution can be obtained from multilevel dynamic computations (e.g. Hibler 1980) using the ice-thickness distribution theory developed by Thorndike and others (1975), the treatment used here is regarded as a first-order attempt to include a range of thicknesses in the model thermodynamics.

Under growth conditions the snow cover is similarly partitioned into a seven-level linear distribution of snow depths. This strategey is based on the assumption that thin (new) ice will generally be covered by less snow than will thick (old) ice. Under melt conditions, which generally occur in spring and summer after much of the snow has been subjected to considerable blowing and drifting, the snow is assumed to be uniformly distributed over the icecovered portion of each grid cell. The snow distribution corresponding to melt conditions is imposed whenever the surface temperature exceeds $0^{\circ} \mathrm{C}$ at the surface of ice of thickness $h_{\text {eff }}$.

\section{METEOROLOGICAL FORCING DATA}

The model is run with a one-day timestep using observed atmospheric forcing data from the period 1961 to 1980 , inclusive. Daily wind fields are computed geostrophically from the National Center for Atmospheric Research (NCAR) set of northern-hemisphere sea-level pressure analyses, which are in the form of $5 \times 5^{\circ}$ latitude-longitude grids. Conversion to the Cartesian coordinates of the ice model is accomplished by bilinear interpolation. A total of 7300 daily pressure grids were required for the 20-year simulations.

Air temperature anomalies are obtained from the so-called "Russian surface temperature data set" (Vinnikov 1977, Robock 1982), which contains monthly temperature anomalies for the northern hemisphere on a $5 \times 10^{\circ}$ latitude-longitude grid. These anomalies are added to the climatological monthly mean temperatures of Crutcher and Meserve (1970) and interpolated bilinearly to the ice model grid. Daily temperatures are then computed by a cubic spline interpolation from the monthly values, which are assumed to correspond to the mid-points of the respective calendar months.

Because the Russian temperature tape available for th is work ended with December 1976, monthly climatological mean temperatures were used for the final four years $(1977-80)$. The monthly means were computed from the temperatures of the first 16 years $(1961-76)$ of the simulation period.

The relative humidities required for the computation of the downcoming longwave radiation were assumed to be $90 \%$ at all times and grid points. 
Earlier tests based on the years 1973-75 had shown that the results were quite insensitive to this assumption.

Finally, the absence of snowfall data for the Arctic required the use of the climatological snowaccumulation rates described in section $2(\mathrm{~b})$. The model sensitivity to interannual snowfall variations may indeed be considerable and will be investigated in the near future.

\section{RESULTS}

The simulations were initiated with thickness fields varying 1 inearly from 0 at the lateral boundaries to $3 \mathrm{~m}$ at the center of the grid. A twoyear "spin-up" using observational data for 1961-62 was then performed before the 1961-80 simulation. Earlier tests with data for 1973-75 (Hibler and Walsh 1982) showed that the simulated fields of thickness, drift and compactness were with in $5 \%$ of periodic equilibrium by the third year of this type of spin-up. The model was therefore run for 22 years of simulation time, al though the results from the two-year spin-up are not included in the following discussion.

Two simulations were performed in order to identify the effects of the model dynamics. In the first, hereafter denoted as simulation DT, both dynamics and thermodynamics were included. In the second, hereafter denoted as simulation $T$, only the model thermodynamics were included. Simulation $T$ is therefore characterized by an absence of both ice motion and open-water areas (leads) in grid cells containing ice. The model running times on the NCAR Cray-1 computer were approximately $11 \mathrm{~min}^{-1}$ for DT and $0.5 \mathrm{~min}^{-1}$ for $T$.

Figure 2 shows the monthly time series of the total ice mass in each simulation. The total ice mass is the sum over all grid cells of the mass of ice in the cell. While a strong seasonal cycle is apparent in both time series of Figure 2, the amplitude is considerably smaller in T than in DT because of the smaller summer melt in $T$. Because the differences in summer melt are attributable primarily to the absence of leads in $T$, the difference in ice volume may be considered an upper bound on the true effect of dynamics in the Arctic. In reality, leads are formed by both thermodynamic and dynamic processes. Additonal insight would be provided by a simulation in which a small fraction of open water is permitted to vary seasonally in $T$. The summer melt process would then be accelerated in T as well as in DT by the absorption of solar radiation in open-water areas with in the pack.

Superimposed on the annual cycles of Figure 2 are low-frequency (multiyear) fluctuations. The results for both DT and T show a tendency for more ice in the middle 1960 s, less ice in the late 1960 s and early 1970 s, and more ice in the middle 1970s. The multiyear fluctuations are compatible with the tabulations of Arctic temperatures of Kelly and others (1982), which show a tendency (albeit irregular) for a slight warming from the middle 1960 s to the early 1970 s. The results for 1977-80 cannot be interpreted in this context because they are based on Climatological thermodynamics.

The largest departures from observed ice extent are found in the winter North Atlantic, where the simulated ice edge is south of the observed edge by 5 to $10^{\circ}$ latitude. Recent simulations by $\mathrm{Hibler}$ and Bryan (private communication) have shown that a more realistic North Atlantic ice edge is obtained when the ice model is coupled to a multilevel ocean model. Interestingly, this improvement is attributable primarily to deep convection near the ice edge rather than to lateral heat transport by ocean currents.

In order to examine ice fluctuations on a regional

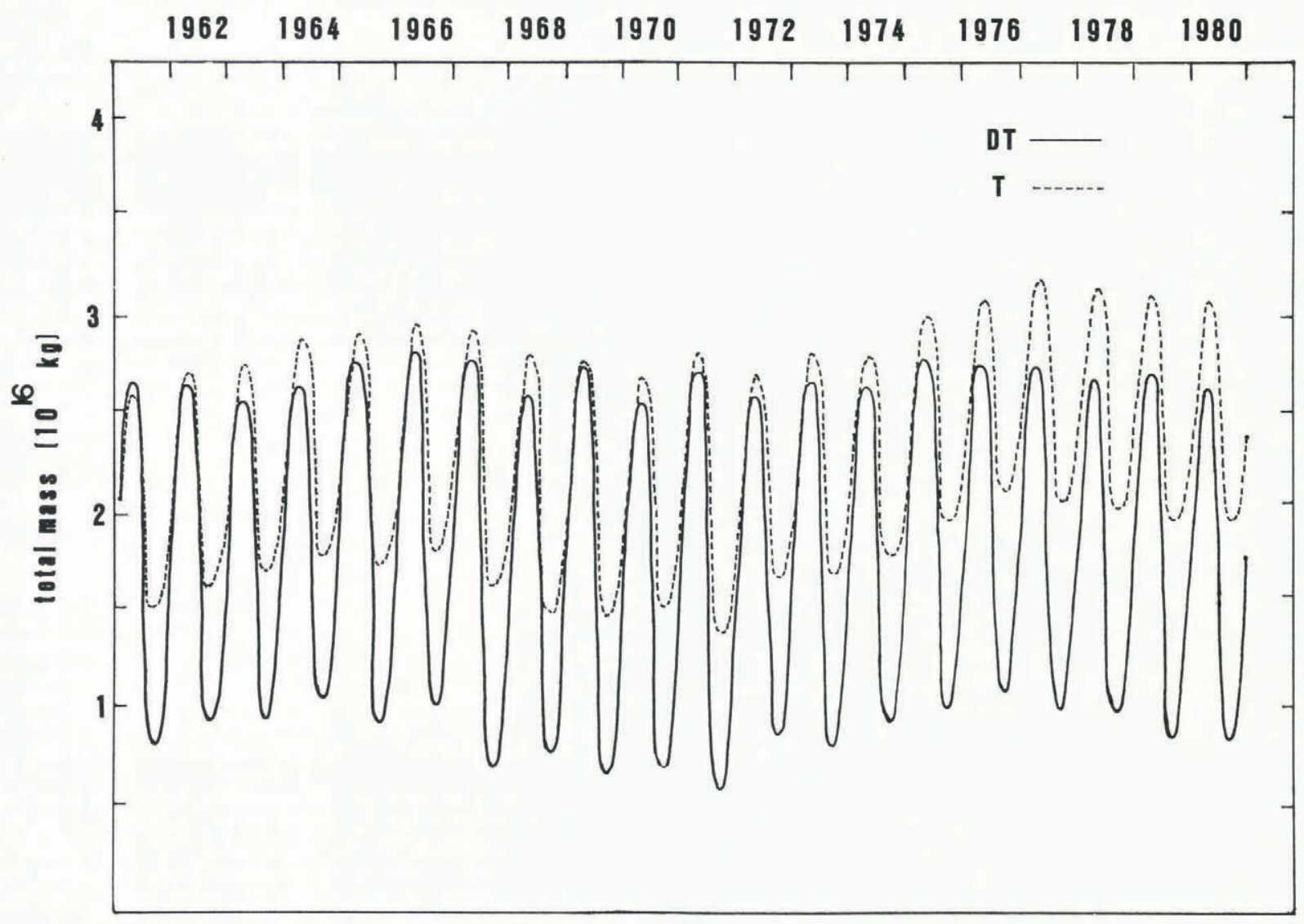

Fig.2. Time series of total ice mass in the complete dynamic-thermodynamic simulation DT and the simulation with only thermodynamics $T$. 
basis, the domain was subdivided into the seven geographical sectors shown in Figure 1 . Regions 2 and 3 are the eastern and western portions of the Arctic Basin, while regions $1,4,5,6$ and 7 contain the seasonal sea-ice zones of the peripheral seas. For each region, the monthly ice contents were converted to departures from normal by subtracting the 20-year mean for the appropriate region and calendar month. Figure 3 shows the time series of these departures for regions $1,2,3,5$ and for the entire grid. Results are shown for both simulations, DT (solid) and $T$ (dashed). The seasonal nature of Bering Sea ice (region 1) is apparent in Figure $3(\mathrm{a})$, as the ice-free summers are characterized by a return to "normal". Most winters during the period 1961-76 contain anomalies of only one sign in the Bering Sea. The time

[a] REGION I

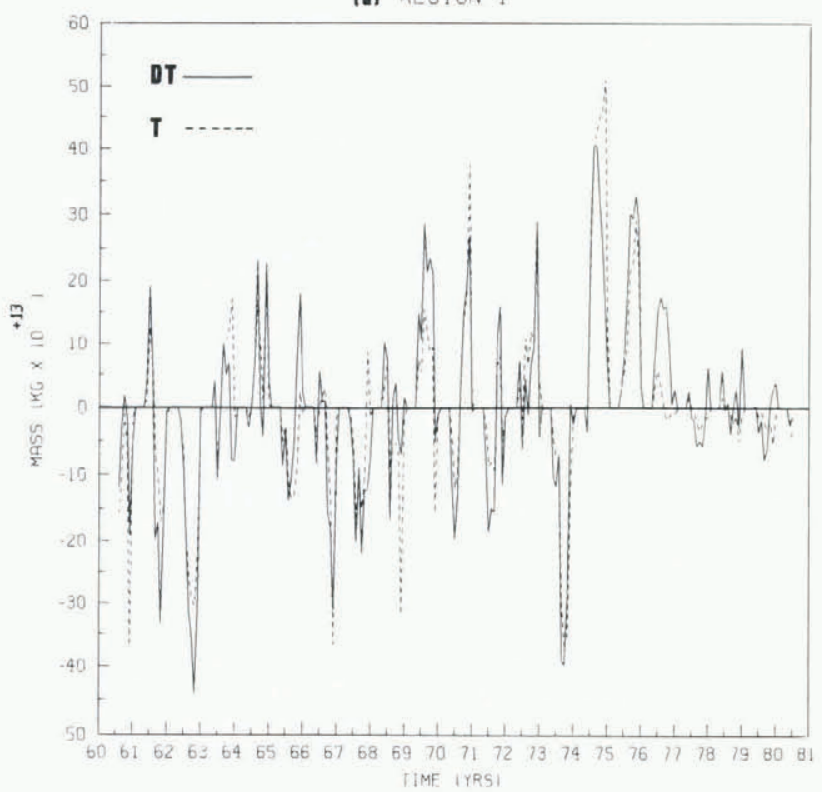

(b) REGION 2

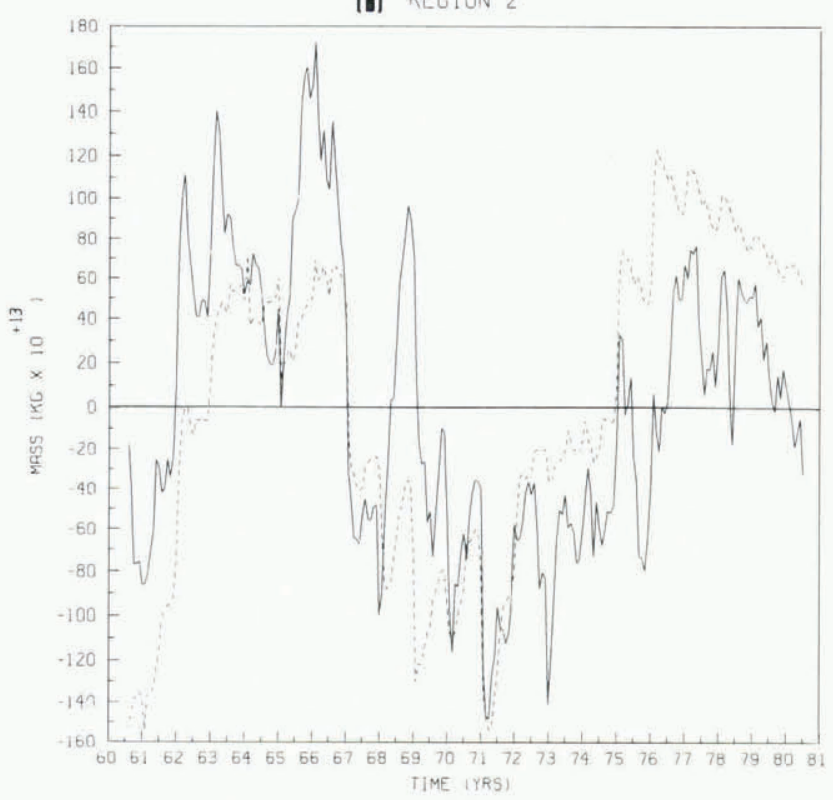

Fig.3. Time series of departures from 20-year monthly ice mass in (a) region 1 , (b) region 2 , (c) region 3 , (d) region 5, and (e) the entire domain. Results are shown for simulation DT (solid line) and simulation $T$ (dashed 1 ine). Horizontal ax is indicates year.

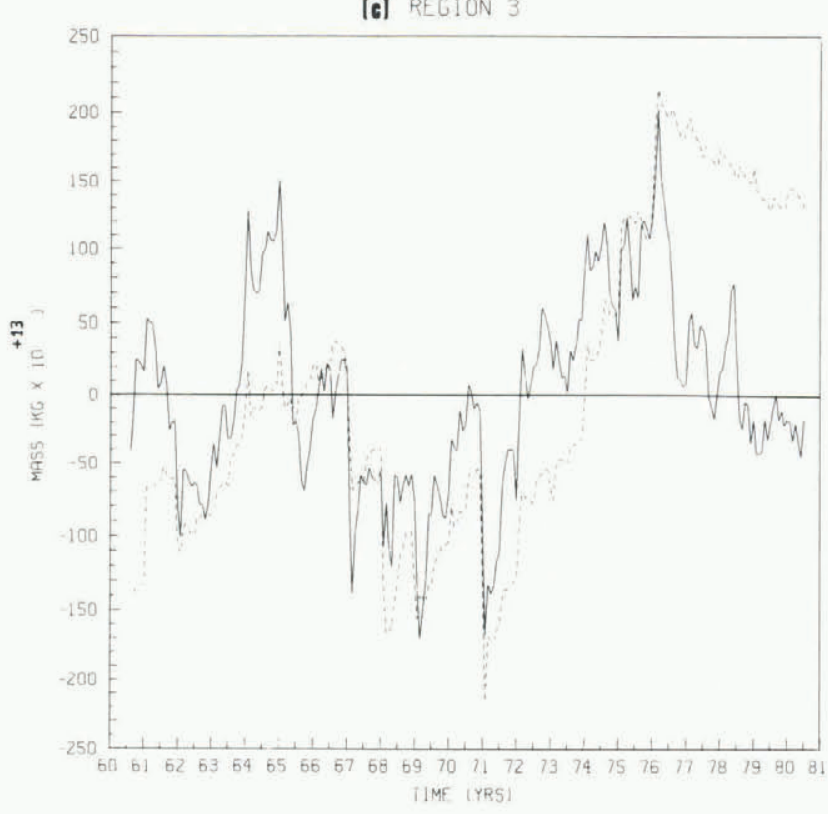

(d) REGION 5

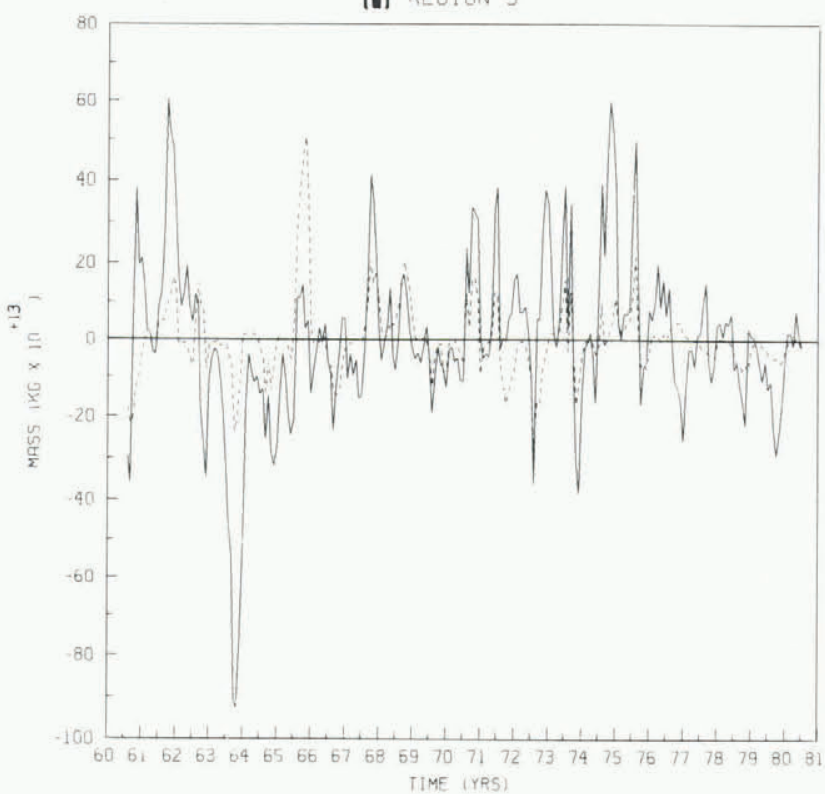

lol Entlro domalo

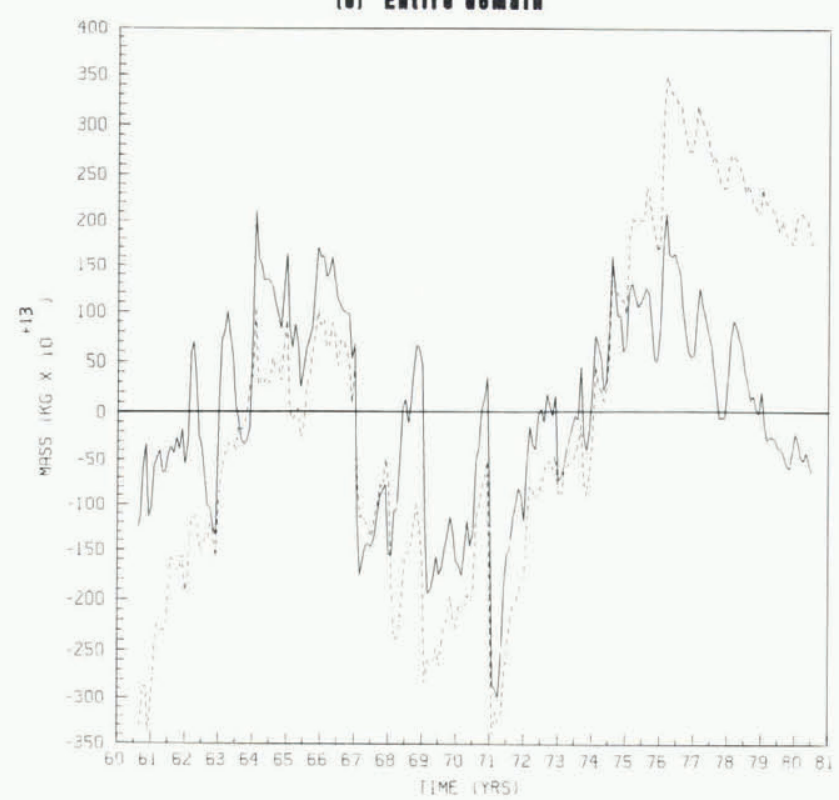



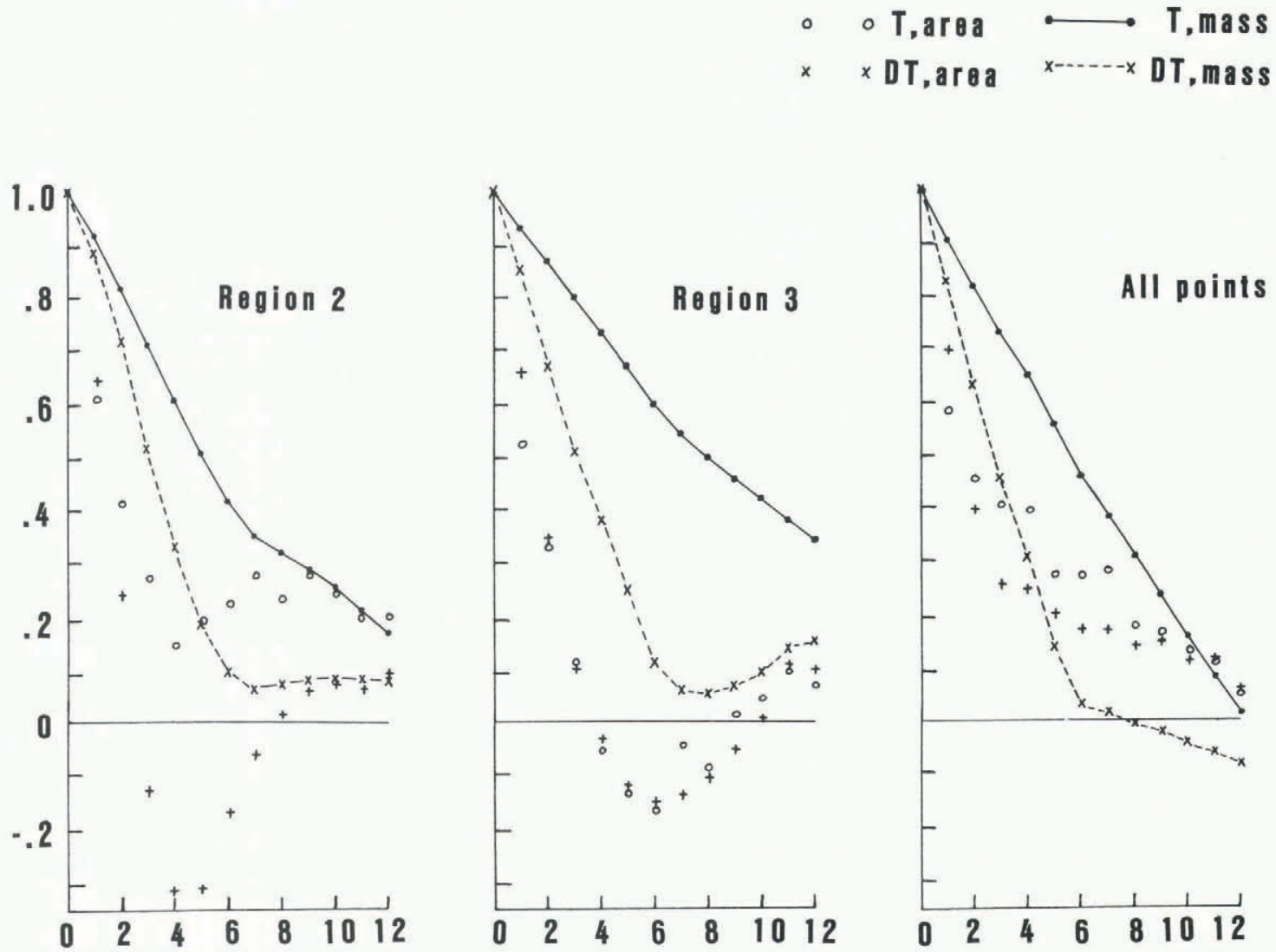

\section{lag [months]}

Fig.4. Autocorrelations of departures from monthly mean ice mass and ice-covered area in regions 2, 3, and the entire domain. Results are shown for the dynamic-thermodynamic simulation DT and the thermodynamic simulation $T$.

series for region 5 contains large positive anomalies from 1961 and 1962 in simulation DT but not in simulation T. As will be shown later in this section, 1961 and 1962 were among the years with the largest ice transports from the Arctic Bas in into the East Greenland Sea. Because the ice thicknesses and icecovered areas are generally much larger in the Arctic Bas in than in the peripheral seas, the anomalies of ice mass are larger in regions 2 and 3 (Fig.3(b) and $(c)$ ) than in the other regions. In fact, the major portion of the mass anomalies for the entire domain (Figs.2 and $3(\mathrm{e})$ ) are provided by regions 2 and 3 . The time series in Figure $3(b)$ and $(c)$ contain relative minima from the late 1960 s to the early 1970s. This feature is found in both simulations and in both regions 2 and 3 . However, considerably more short-term ( monthly) variability is apparent in DT than in T. Large-scale transport on the monthly time scale evidently results in wider and more frequent excursions from the 20-year mean. Figure 4 is a quantitative illustration of the tendency for anomalies to persist more strongly in the absence of dynamical processes. In both simulations, the autocorrelations of the mass anomalies decay systematically with lag in regions 2 and 3 as well as in the entire domain. The pers istence is generally greater in region 3 (western Arctic) than in region 2 (eastern Arctic). However, the persistences are consistently greater for simulation $T$ than for DT. At a lag of six months, for example, the following percentages of the variance of mass are described by persistence in simulations (T, DT): $(17 \%, 1 \%)$ in region $2,(36 \%, 2 \%)$ in region 3 , and $(22 \%, 1 \%)$ in the entire domain. The persistences of the anomalies of the ice-covered areas with in the seven regions decay to 0 more rapidly because of the seasonal nature of the ice-covered area (zero summer coverage in the peripheral seas, $\sim 99 \%$ winter coverage in the Arctic Basin). Figure 5 illustrates the behavior of the ice-covered area. While the seasonality is evident in Figure $5(a),(b)$ and (c) for regions 1,2 and 3 , the corresponding plot for the entire domain (Fig.5(d)) shows the rapid variability of the ice-covered area. This variability contrasts with the relatively slow evolution of the thickness (mass) anomalies, but is cons istent with the high-frequency fluctuations in plots of areal ice coverage based on observational data (Walsh and Johnson 1979: fig.5(a)).

Finally, Figure 6 shows the time series of the simulated outflow of ice from the Arctic Basin into the Fram Strait. The plotted values are the mass fluxes across the boundary between regions 3 and 5 (Fig.1). A strong annual cycle is apparent in the mean seasonal outflow, which is much greater in winter and spring than in summer. The seasonality results from both the greater ice thicknesses and the stronger wind-induced ice velocities during the winter/spring portion of the year. A large amount of interannual variability is also apparent in Figure 6 . The annual total outflow $\left(\mathrm{km}^{3}\right)$, for example, ranges from 408 (in 1964) and 541 (in 1963) to 2109 (in 1962) and 2118 (in 1975). These large interannual excursions are likely to play significant roles in the mass budgets of the various subregions of the Arctic and the peripheral seas. A more detailed examination of the regional mass budgets is now underway. 
[a] REGION 1

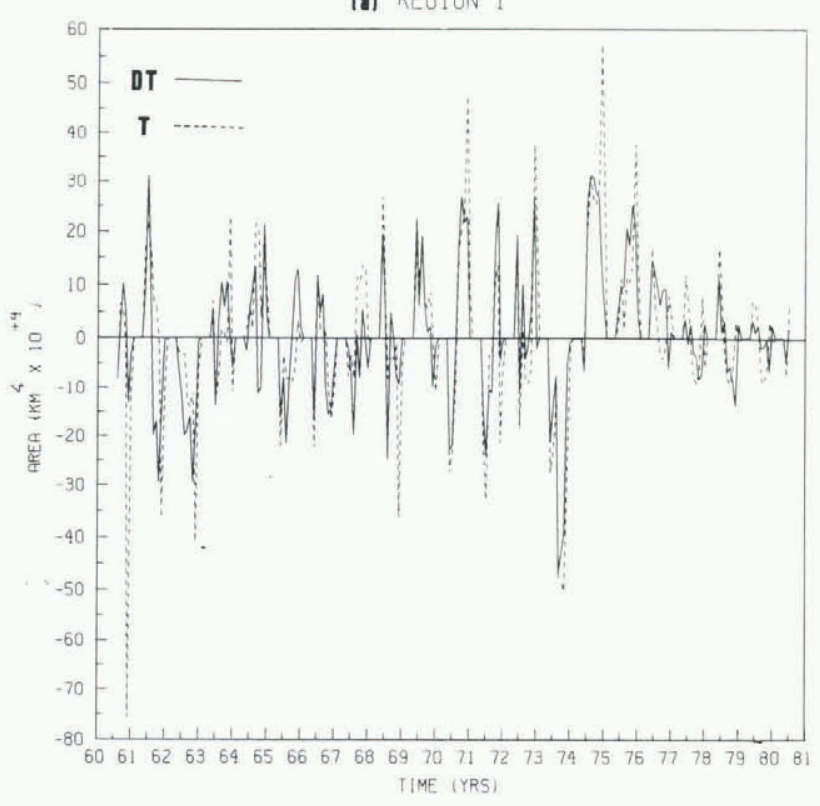

[c] REGION 3

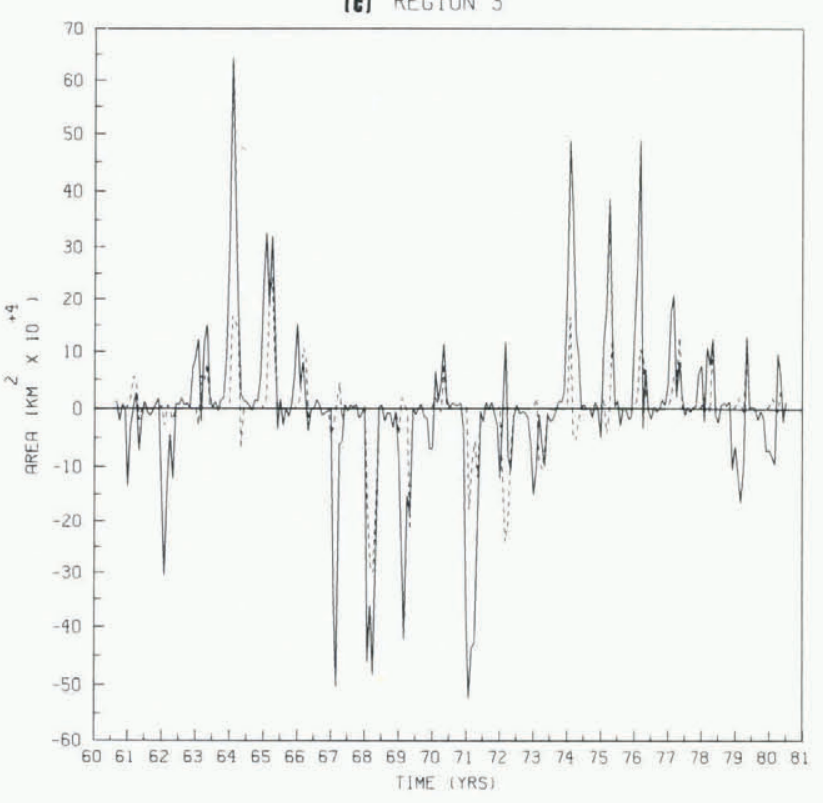

(b) REGION 2

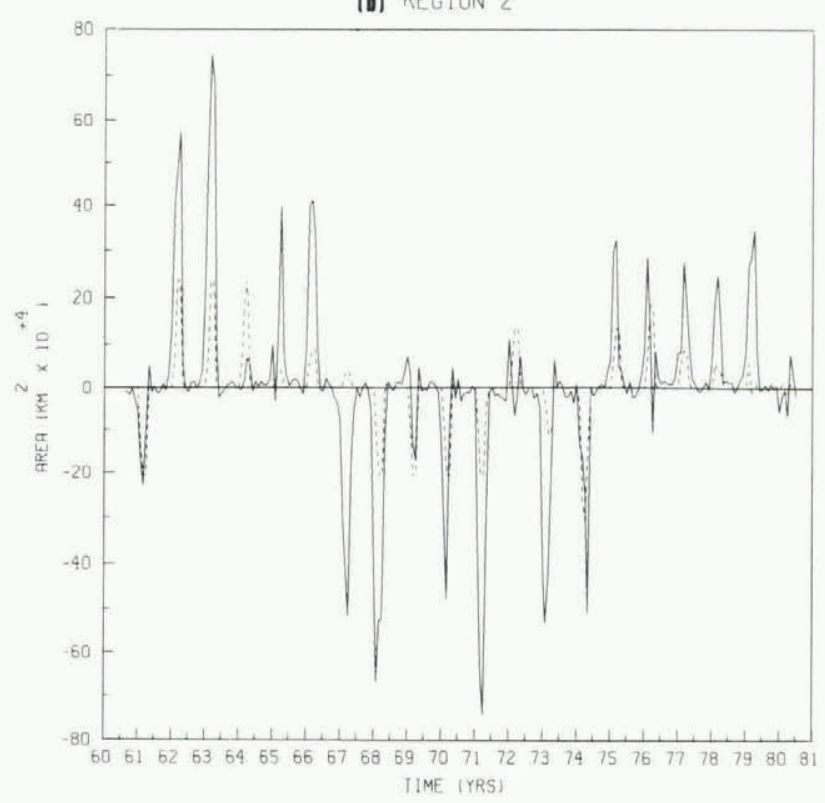

[d] Entire domain

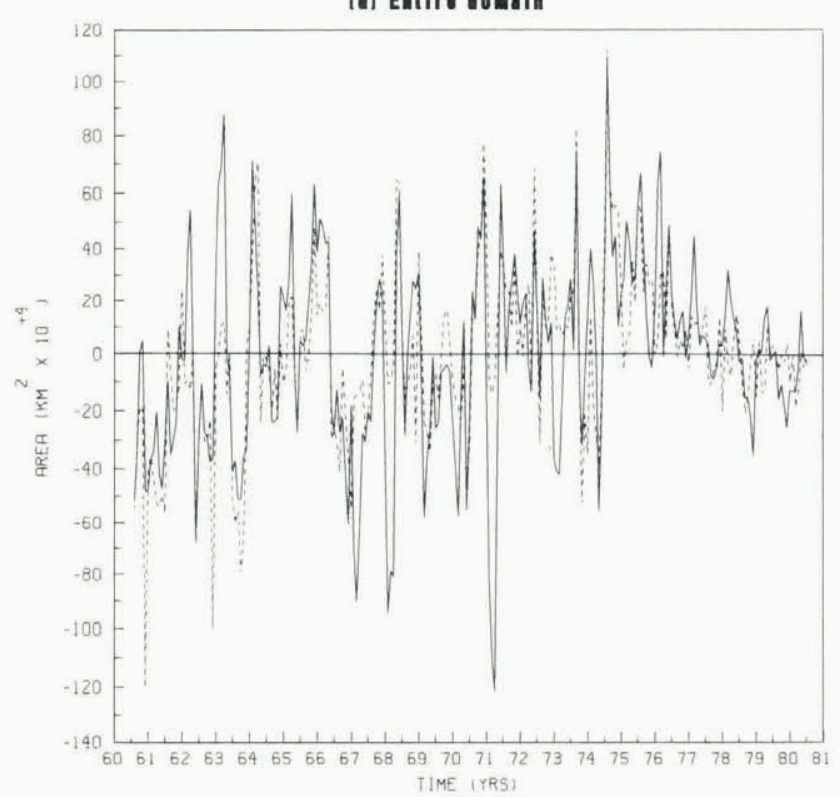

Fig.5. Time series of departures from 20-year monthly mean ice-covered area in (a) region 1 , (b) region 2, (c) region 3 , and (d) the entire domain. Results are shown for simulation DT (solid line) and simulation $\mathrm{T}$ (dashed line). Horizontal axis indicates year.

\section{CONCLUSIONS}

This paper has described some initial results from a simulation of northern hemisphere sea-ice fluctuations over a 20-year period. Considerable experimentation remains to be done, especially regarding the sensitivity to the input temperature data and the snow-accumulation rates. Nevertheless, several findings described in section 4 are noteworthy. Perhaps most importantly, the fluctuations of sea-ice mass, both in the entire domain and in individual subregions, are more persistent than are fluctuations of ice-covered area. It follows that anomalies of ice thickness are largely responsible for the evolution of the large-scale anomalies of ice volume or mass. This conclusion is apparent in the results of the complete dynamicthermodynamic simulation as well as the simulation with only thermodynamics, even though the former produces a much larger seasonal amplitude of the simulated ice mass. However, the inclusion of dynamic processes does tend to introduce more highfrequency variability into the regional (and total) amounts of ice mass.

The time series of the mass and area anomalies contain several multiyear fluctuations with in the 20-year simulation period: relatively large amounts of ice in the early and middle 1960s and the middle $1970 \mathrm{~s}$, and relatively little ice in the late 1960s and early 1970s. These fluctuations are generally consistent with the high-latitude surface-temperature anomalies of Kelly and others (1982).

The simulated annual ice export from the Arctic Basin into the East Greenland Sea varies by factors of 3 to 4 . The role of dynamical processes in the 
[a] Soasonal mean

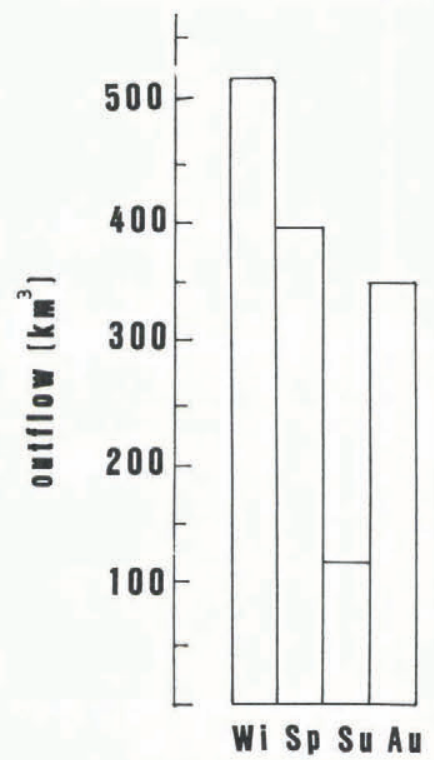

[b] Annual

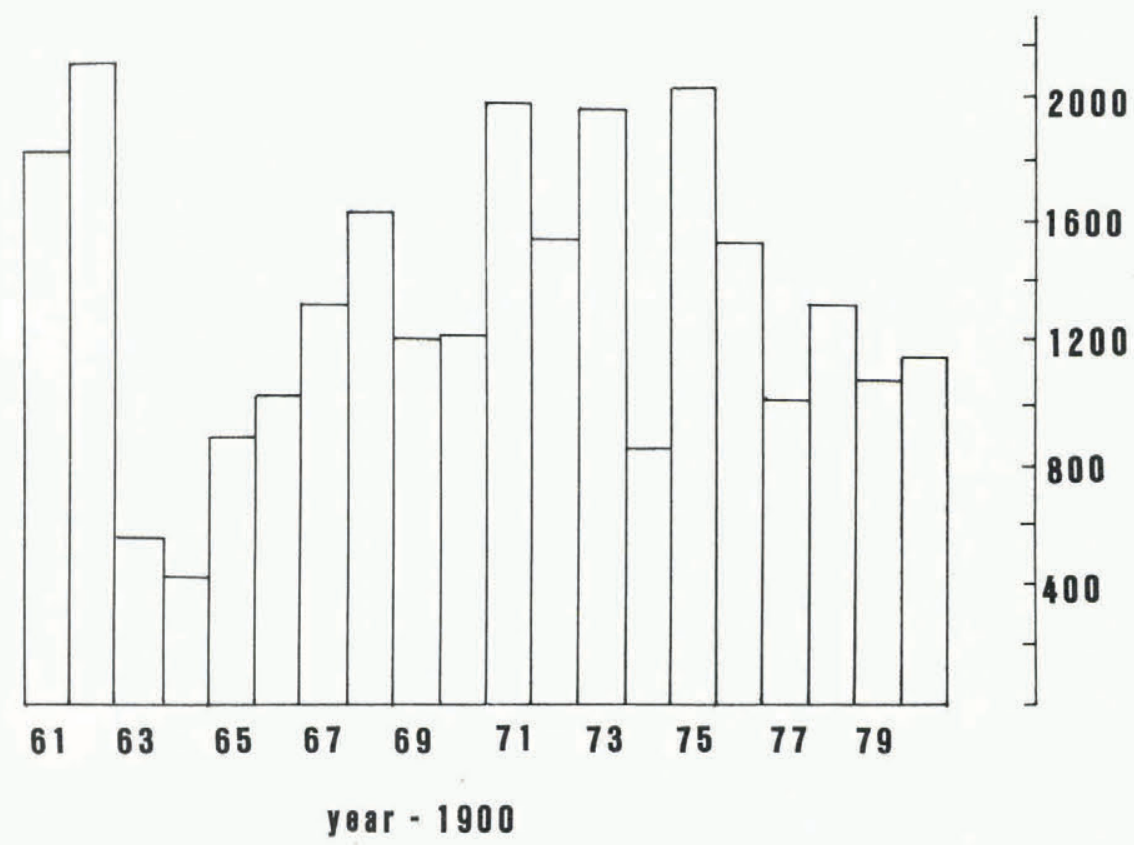

Fig.6. Outflow of ice $\left(\mathrm{km}^{3}\right)$ from central Arctic into East Greenland Sea. 20-year seasonal means are shown in (a) where $W i$ is winter, $S p$ is spring, $S u$ is summer and Au is autumn. Annual totals are shown in (b).

variability of the regional mass budgets has yet to be evaluated in detail, although an adequate description of the large-scale fluctuations is almost certain to involve sea-ice dynamics as well as thermodynamics.

\section{ACKNOWLEDGMENTS}

This work is supported by the National Science Foundation, Division of Polar Programs, through grant DPP81-20134. Computing time was provided by NCAR.

\section{REFERENCES}

Crutcher H L, Meserve J M 1970 Selected level heights, temperatures, and dew points for the northern hemisphere. Washington, DC, US Naval Weather Service Command (NAVAIR Report 50-1C-52)

Hibler W D III 1979 A dynamic thermodynamic sea ice model. Journal of Physical Oceanography 9(4): 815-846

Hibler W D III 1980 Modeling a variable thickness sea ice cover. Monthly Weather Review 108(12): 1943-1973

Hibler W D III, Walsh J E 1982 On modeling seasonal and interannual fluctuations of Arctic sea ice. Joumal of Physical Oceanography 12(12): 1514-1523

Kelly P M 1978 Forecasting the Arctic sea ice on time scales of a few months to many years. Climate Monitor 7(3): 95-99

Kelly P M, Jones P D, Sear C B, Cherry B S G, Tavakol R K 1982 Variations in surface air temperatures. Part II: Arctic regions, 1881-1980. Monthly Weather Review 110(2): 71-83

Lemke P, Trinkl E W, Hasselmann K 1980 Stochastic dynamic analys is of polar sea ice variability. Joumal of Physical Oceanography 10(12): 2100-2120

LeSchack L A, Hibler W D III, Morse F H 1971 Automatic processing of Arctic pack ice data obtained by means of submarine sonar and other remote sensing techniques. AGARD Conference Proceedings 90: $5-1-5-19$
Manabe S, Stouffer R J 1980 Sensitivity of a global cl imate model to an increase of $\mathrm{CO}_{2}$ concentration in the atmosphere. Joumal of Geophysical Research 85(C10): 5529-5554

Maykut G A 1982 Large-scale heat exchange and ice production in the central Arctic. Joumal of Geophysical Research 87(C10): 7971-7984

Parkinson C L, Kellogg W W 1979 Arctic sea ice decay simulated for a $\mathrm{CO}_{2}$-induced temperature $r$ ise. Climatic Change 2(2): 149-162

Parkinson C L, Washington W M 1979 A large-scale numerical model of sea ice. Joumal of Geophysical Research 84(C1): 311-337

Robock A 1982 The Russian surface temperature data set. Jourmal of Applied Meteorology 21(12): 1781-1785

Rogers J C 1978 Meteorological factors affecting interannual variability of summertime ice extent in the Beaufort Sea. Monthly Weather Review 106(6): 890-897

Sanderson R M 1975 Changes in the area of Arctic sea ice, 1966 to 1974. Meteorological Magazine 104(1240): 313-323

Smirnov V I 1980 Oppozitsiya $v$ pereraspredelenii 1 'da $v$ vodakh zarubezhnoy Arktik $i$ [Opposition in ice redistribution in the waters of the foreign Arctic]. Meteorologiya $i$ Gidrologiya 1980(3): 73-77

Thorndike A S, Rothrock D A, Maykut G A, Colony R 1975 The thickness distribution of sea ice. Joumal of Geophysical Research 80(33): 4501-4513

Vinnikov K Ya 1977 K voprosu o metodike polucheniya $i$ interpretatsii dannykh ob izmenen ii prizemnoy temperatury vozdukha severnogo polushariya za period 1881-1975 gg [On the problem of the method for obtaining and interpreting data on surface air temperature in the northern hemisphere during the period 1881-1975]. Meteorologiya $i$ Gidrologiya 1980(9): 110-114

Walsh J E, Johnson C M 1979 An analys is of Arctic sea ice fluctuations, 1953-77. Journal of Physical oceanography 9(3): 580-591

Washington $W M$, Semtner $A J$ Jr, Meeh 1 G A, Knight $D J$, Mayer T A 1980 A general circulation experiment with a coupled atmosphere, ocean and sea ice model. Joumal of Physical Oceanography 10(12): 1887-1908 